\title{
A cobertura de ciência em telejornais do Brasil e da Colômbia: um estudo comparativo das construções midiáticas
}

\section{The coverage of science in television news programs in Brazil and Colombia: a comparative study of media constructs}

\section{Marina Ramalho}

Pesquisadora, Núcleo de Estudos da Divulgação Científica (NEDC)/ Museu da Vida (MV)/Casa de Oswaldo Cruz (COC)/Fiocruz.

marinar@coc.fiocruz.br

\section{Tania Arboleda}

Pesquisadora independente. Carrera 21 34-34

1111311 - Bogotá DC - Colômbia

taniaarboleda@gmail.com

\section{Daniel Hermelin}

Professor, Departamento de Comunicação Social/

Universidad Eafit.

Carrera 49N 7 Sur, 50,

bloque 38 , oficina 532

05001000 - Medellín ANT - Colômbia

dhermeli@eafit.edu.co

\section{Gabriela Reznik \\ Mestranda, NEDC/MV/COC/ Fiocruz.}

gabriela_reznik@hotmail.com

\section{Luisa Massarani}

Pesquisadora, NEDC/MV/COC/ Fiocruz.

lumassa@fiocruz.br

NEDC/MV/COC/Fiocruz.

Avenida Brasil, 4.365 21045-360 - Rio de Janeiro RJ - Brasil
RAMALHO, Marina et al. A cobertura de ciência em telejornais do Brasil e da Colômbia: um estudo comparativo das construções midiáticas. História, Ciências, Saúde-Manguinhos, Rio de Janeiro, v.24, n.1, jan.-mar. 2017, p.223-242.

\section{Resumo}

O estudo analisa e compara a cobertura de ciência e tecnologia do principal telejornal do Brasil (Jornal Nacional) e o da Colômbia (Noticias Caracol), utilizando análise de conteúdo aplicada a um corpus de matérias representativas de um ano de transmissão - abril 2009 a março 2010. Observou-se que o informativo brasileiro apresentou mais que o dobro de matérias sobre ciência e tecnologia que o colombiano, com cobertura mais estável ao longo do ano e notas mais longas, mais recursos visuais e maior destaque. Porém, foram encontradas similaridades nos dois telejornais: notícias sobre medicina e saúde foram as mais frequentes; o principal enfoque das notas foi o anúncio de nova investigação; cientistas foram as principais fontes citadas; e pesquisas nacionais foram priorizadas.

Palavras-chave: ciência e tecnologia; Jornal Nacional; Noticias Caracol.

\section{Abstract}

This study analyzes and compares the science and technology coverage in Brazil's main television news program (Jornal Nacional) and its Colombian counterpart (Noticias Caracol). Using content analysis, we investigated a corpus of news stories broadcast from April 2009 to March 2010. We found that Jornal Nacional presented over twice as many reports on science and technology as Noticias Caracol, and that its levels of reporting remained fairly stable throughout the year. The Brazilian reports were also longer, were featured more prominently, and used more visual resources. Even so, some similarities were found: news about health and medicine was most frequent; the reports focused primarily on announcing new research; scientists were the main sources cited; and national research was prioritized.

Keywords: science and technology; Jornal Nacional; Noticias Caracol. 
Com om os avanços tecnocientíficos cada vez mais acelerados das últimas décadas, os cidadãos são confrontados a todo momento com decisões cotidianas que demandam algum tipo de conhecimento científico, ainda que o façam de forma inconsciente: no supermercado, por exemplo, ao decidir entre um alimento transgênico ou não; ao optar por um determinado tratamento para algum tipo de doença; ou ainda ao identificar se sua moradia está situada em um local de risco ou não.

Muitos autores e profissionais do campo da divulgação científica defendem que, para exercer sua cidadania de forma mais plena, é preciso que a população tenha acesso ao que vem sendo produzido pela comunidade científica mundo afora, a fim de poder fazer suas escolhas de maneira mais consciente e poder participar do debate político na área. Isso é particularmente relevante quando se considera que grande parte da pesquisa científica mundial é financiada por dinheiro público - como é o caso no Brasil e na Colômbia, onde a maior fração das pesquisas é realizada em universidades e instituições públicas, e onde a aliança academia-empresa-Estado é ainda incipiente -, o que demandaria, dos pesquisadores, uma espécie de prestação de contas à sociedade, assim como a outros atores que se apropriam do conhecimento produzido pelos cientistas (ver, por exemplo, Lozano, 2005; Hermelin, 2011).

São controversas, no entanto, as opiniões sobre quais informações científicas seriam de fato relevantes para se divulgar ao público "leigo" diante da avalanche de informações à qual está submetido diariamente. Também variam os pontos de vista sobre que quantidade de informações (e em que profundidade) uma pessoa deveria deter para ser considerada bem informada em ciência. Porém, a importância da democratização das informações científicas e suas aplicações parece ser um ponto de contato entre tais autores - um assunto que também implica diversos debates sobre quais são os "conhecimentos válidos" e em que contexto, como discutido por Pérez-Bustos e Lozano-Borda (2011).

Em países considerados "em desenvolvimento" - onde, em geral, existe grande exclusão social no que se refere a bens culturais, incluídos os científicos -, para grande parte da população que já completou o ensino formal, a principal ponte de contato com a comunidade científica são os meios de comunicação de massa. Uma pesquisa nacional de percepção pública sobre ciência e tecnologia realizada na Colômbia em 2013 (Daza-Caicedo, LozanoBorda, 2014) constatou, por exemplo, que os meios de comunicação eram os principais responsáveis por despertar o interesse dos respondentes por temas de ciência e tecnologia (C\&T) (foram mencionados por 24,5\% das pessoas), seguidos por família (23\%) - as outras opções de resposta, nessa questão, eram universidade, trabalho, amigos ou conhecidos, colégio e outros. A mesma pesquisa revelou ainda que, entre os meios de comunicação, a principal fonte utilizada pelos respondentes para se informar sobre ciência foi a televisão (62\%), seguida por internet (30\%). Também para temas de tecnologia, a TV é a fonte mais consultada (por $53,1 \%)$, seguida pela internet (40\%).

No Brasil, onde 97,2\% das residências em 2013 possuíam televisão (IBGE, 18 set. 2014) valor superior, por exemplo, ao percentual de lares com rádio: 75,8\% -, a TV também tem papel preponderante como fonte de informação em C\&T. De acordo com enquete nacional de percepção pública da ciência e tecnologia realizada pelo Ministério da Ciência, Tecnologia e Inovação e pelo Centro de Gestão e Estudos Estratégicos (Brasil, 2015), 70\% dos entrevistados 
afirmaram assistir a programas televisivos de C\&T, e 37\% afirmaram ler sobre C\&T em jornais impressos.

As pesquisas citadas constataram ainda que há interesse por temas de C\&T entre os cidadãos entrevistados. Na pesquisa colombiana, para a pergunta "Você tem interesse por ciência e tecnologia?", 74,3\% das pessoas disseram que sim. Já para a questão "Com quais dos seguintes temas você se entretém?", ciência foi citada por 62,8\% dos respondentes. Outros temas relacionados com ciência também foram mencionados por parte significativa dos entrevistados: medicina e saúde (57,3\%), meio ambiente e ecologia (54,9\%), e educação $(61,7 \%)$. No Brasil, 61\% declararam interesse por ciência e tecnologia, 78\% por medicina e saúde, e $78 \%$ por meio ambiente.

Dada a ampla penetração da televisão no cotidiano dos cidadãos latino-americanos e do uso difundido desse meio como fonte de informação em geral e sobre C\&T, não é exagero afirmar que a TV tem papel relevante na forma como esses cidadãos percebem a atividade científica e seus atores. Não se propõe aqui uma relação direta de causa e efeito, como o faziam teorias mais antigas da comunicação - como da "agulha hipodérmica" ou outras teorias próprias dos "efeitos diretos" -, mas se chama a atenção para a TV como uma mediação fundamental na maneira como representações da ciência e da tecnologia são construídas entre os cidadãos. Por isso a importância de se estudar como a ciência é transmitida na televisão - sobretudo em programas com altos índices de audiência -, identificando, por exemplo, quais temas são destacados ou deixados à margem, que abordagens são privilegiadas, que narrativas são preponderantes, e quais atores sociais são convidados a opinar. Análises desse tipo podem oferecer indícios importantes para estudos qualitativos sobre as representações sociais a respeito da C\&T, além de verificar se a demanda dos telespectadores por esse tipo de tema é atendida. Isso é particularmente relevante se levamos em conta o papel que têm os meios de comunicação de massa na coesão social e no empoderamento das culturas populares, em particular no âmbito latino-americano (ver, por exemplo, Yúdice, 2008).

Nos EUA e na Europa, há vários estudos que se dedicam a analisar como a mídia - sobretudo jornais impressos e TV - aborda temas de C\&T (alguns exemplos são: Bucchi, Mazzolini, 2003; Hijmans, Plejter, Wester, 2003; Pellechia, 1997; Bauer, Ragnarsdóttir, Rúdólfsdóttir, 1993; Hansen, Dickinson, 1992). Alguns trabalhos abordam a questão de forma comparativa entre países (Lehmkuhl et al., 2012; Verhoeven, 2010; León, 2008; Göpfert, 1996). Na América Latina, no entanto, são menos frequentes os estudos que se debruçam sobre a ciência e tecnologia nos meios de comunicação (Arboleda, Hermelin, Pérez-Bustos, 2011; Medeiros, Ramalho, Massarani, 2010; Takahashi, Meisner, 2013; Polino, Fazio, Chiappe, 2006). Menos frequentes ainda são aqueles que tratam da questão pela perspectiva comparativa entre países, como Almeida et al. (2011), Massarani e Buys (2008) e Massarani et al. (2005).

Na Colômbia, alguns poucos estudos dão conta da baixa presença de temáticas científicas na mídia e evidenciam, ainda, alguns aspectos como a localização pouco prioritária dada a esses temas nas edições; a predominância da utilização de uma única fonte de informação, sobretudo as fontes do governo; a pouca contextualização quanto à relação da C\&T com tópicos da vida nacional; a apresentação das informações em forma de resultados e a priorização de acontecimentos internacionais sobre os nacionais (Gómez-Giraldo et al., 2010; Rozo, 2006; Bonilla, Cadavid-Bringe, 2004). Tais resultados se assemelham aos encontrados em outros 
estudos sobre a cobertura de ciência na imprensa escrita de outros países da América Latina (Almeida et al., 2011; Parodi, Ferrari, 2007; Amorim, Massarani, 2008; Bustos Mora, 2004). Já no Brasil, estudos que se dedicaram à cobertura de $C \& T$ em telejornais do país verificaram a existência de um espaço mais relevante para esses temas na agenda informativa desses meios (Ramalho, Polino, Massarani, 2012; Alberguini, 2007; Andrade, 2004).

O presente estudo busca analisar e comparar como o principal telejornal do Brasil e o da Colômbia (Jornal Nacional e Noticias Caracol, respectivamente) tratam assuntos de C\&T no período de um ano (abril de 2009 a março de 2010). Trata-se de parte de um projeto mais amplo que visa mapear a cobertura de C\&T em telejornais da América Latina e de um desdobramento dos trabalhos de Ramalho, Polino e Massarani (2012) no Brasil e de Arboleda, Hermelin, Perez-Bustos (2011), e Arboleda et al. (2015) na Colômbia. Além disso, consiste numa comparação pertinente ao levar-se em conta que são os dois países de maior população na América do Sul, com economias consideradas "emergentes", que vêm tendo, durante muito tempo, índices de desigualdade social particularmente altos, embora na última década tenham sido reduzidos os índices de pobreza (IBGE, 18 set. 2014; Dane, 2014; BID, 2014). Vale agregar ainda que, diante de tendências como as que se observam em estudos dessa natureza, há tentativas em ambos os países de fortalecer diversos atores na relação ciência/ sociedade, refletidas em políticas públicas como a Estratégia Nacional de Apropriação Social da Ciência, Tecnologia e Inovação, publicada por Colciencias (Lozano-Borda, Maldonado, 2010), na Colômbia, e, no Brasil, nos planos nacionais de 2007-2010 e 2011-2015 para ciência, tecnologia e inovação e no chamado Livro azul, uma síntese das discussões sobre o futuro da C\&T brasileira na próxima década na quarta Conferência Nacional de Ciência e Tecnologia, realizada em maio de 2010 (Livro azul..., 2010).

\section{Uma metodologia de análise para comparar matérias de ciência na América Latina}

Para este estudo comparativo, foram selecionados telejornais com perfis semelhantes em cada país: o brasileiro Jornal Nacional (JN), da Rede Globo, empresa integrante do maior conglomerado de mídia do país (Globo, 9 jul. 2012), e o colombiano Noticias Caracol (NC), do Canal Caracol, que pertence ao Grupo Valórem, grupo econômico da Família Santo Domingo, um dos mais poderosos da Colômbia, também dono do jornal El Espectador. Os dois telejornais são de redes privadas de TV, exibidos em sinal aberto, em horário nobre, têm abrangência nacional e possuem os maiores índices de audiência em seus países ${ }^{1}$ nessa faixa de horário e tipo de programa. O telejornal brasileiro é transmitido de segunda a sábado, enquanto o colombiano, de segunda a domingo. Para este estudo, foram desconsideradas as edições de domingo ${ }^{2}$ de Noticias Caracol, para não comprometer a comparação dos dados.

O período analisado foi de um ano: de abril de 2009 a março de 2010. Construiu-se uma amostra de programas utilizando a técnica de semana construída (Krippendorff, 1990; Stempel, Westley, 1989), segundo a qual se reduz o universo a ser analisado sem comprometer sua representatividade estatística. Cada mês foi representado por uma semana construída de cada programa, em que os dias da semana foram sorteados aleatoriamente (os mesmos dias para os dois programas). Logo, a amostra total englobou 12 semanas construídas de seis dias (segunda a sábado), ou seja, 72 edições de cada telejornal. 
Depois de definidas as edições para análise, foi preciso selecionar as matérias de ciência, que seriam submetidas à análise de conteúdo. Para isso, elaboraram-se critérios rígidos para definir as características que uma matéria jornalística ${ }^{3}$ deveria apresentar para ser considerada uma notícia de ciência. Assim, utilizando-se como base uma proposta de Rondelli (2004), definiu-se que a matéria de C\&T deveria atender pelo menos a um dos seguintes pré-requisitos: mencionar cientistas, pesquisadores, professores universitários ou especialistas em geral, desde que aparecessem vinculados a uma instituição científica e comentassem temas relacionados à ciência, ou mencionar instituições de pesquisa e universidades; mencionar dados científicos ou resultados de investigações; mencionar política científica; ou tratar de divulgação científica.

Às matérias de ciência foi aplicado um protocolo de análise de conteúdo desenvolvido conjuntamente por pesquisadores da Rede Ibero-americana de Monitoramento e Capacitação em Jornalismo Científico (da qual os autores deste artigo fazem parte). Tal protocolo está descrito detalhadamente em Ramalho et al. (2012). Das variáveis contempladas pelo protocolo, foram selecionadas para este artigo: quantidade e duração das matérias, dias da semana, meses e blocos do telejornal em que foram veiculadas, presença de chamada na abertura do programa, presença de séries de reportagens científicas, áreas de conhecimento abordadas, enquadramentos narrativos utilizados, uso de recomendações, utilização de recursos visuais, fontes e vozes citadas, gênero dos cientistas entrevistados, local onde os cientistas eram retratados e países de origem da notícia.

\section{Resultados e discussão: o que se mostra e o que não se mostra de ciência nos telejornais}

O telejornal brasileiro apresentou mais que o dobro de matérias de ciência (77) que o telejornal colombiano (38) no período analisado - uma média de 1,1 matéria de C\&T por edição do Jornal Nacional e 0,5 no Noticias Caracol. A duração média das matérias brasileiras também foi maior: 135 segundos, contra 101. Quanto à relevância atribuída pelos telejornais às matérias de ciência, pode-se dizer que no JN essas notícias ganharam mais destaque, já que $46,8 \%$ delas contaram com chamada na abertura do programa, quando os âncoras anunciam as principais notícias de uma edição. Em NC, 28,9\% do corpus de matérias teve chamada na abertura. Ainda no telejornal brasileiro, a maior parte das notícias científicas $(42,8 \%)$ foi veiculada no primeiro bloco do programa - quando são transmitidas as notícias de maior impacto da edição -, contra 26,3\% no caso de Noticias Caracol. No entanto, o telejornal colombiano teve uma proporção maior de matérias científicas que integravam séries de reportagens (15,8\%, contra 6,5\%), em que, em geral (mas não necessariamente), as notícias são mais extensas e mais aprofundadas.

Ao observar a distribuição das matérias ao longo da semana, verificou-se que no JN os dias que apresentaram um maior número de notícias científicas foram terça (23,4\% do total de notícias), quinta $(19,5 \%)$ e quarta $(18,2 \%)$. Aos sábados, foram veiculadas apenas 10,4\% das matérias, o que demonstra que a agenda científica desse telejornal está mais concentrada no meio da semana, quando, em geral, está a maioria das hard news, em oposição ao final de semana, que costuma reunir pautas mais atemporais. Já em NC, a distribuição de matérias ao longo da semana foi mais aleatória: os dias com maior quantidade de matérias foram quarta 
e sexta-feira (ambos com 23,7\% das notícias desse telejornal), seguidos por segunda (18,4\%), terça e sábado (ambos com 15,8\%) e quinta-feira, com apenas 2,6\% das notícias.

Também em relação à distribuição das matérias de ciência ao longo dos meses estudados, os telejornais apresentaram tendências muito diferentes (Gráfico 1). O Jornal Nacional teve uma cobertura mais equilibrada durante o ano, com picos discretos nos meses de abril, julho e novembro (respectivamente 13\%, 11,7\% e 11,7\% das notícias). Os meses com menor número de notícias de ciência foram fevereiro, maio e junho. Em fevereiro, a baixa quantidade de matérias de ciência está relacionada ao carnaval, evento que atrai grande cobertura nos programas noticiosos. Já nos meses de maio e junho, a atenção intensa dada pelo telejornal à gripe $\mathrm{A} / \mathrm{H} 1 \mathrm{~N} 1$ pode ter sido a razão para o baixo número de matérias de ciência. Isso porque o tema foi mais abordado segundo enfoques de contenção e alastramento da doença do que pelo ponto de vista de pesquisa científica, como também comprovaram Medeiros e Massarani (2011). Por isso, a maioria das notícias sobre a enfermidade não se enquadrava nos pré-requisitos para ser incluída na amostra de matérias de C\&T que foram analisadas. Além desse acontecimento, a intensa cobertura sobre chuvas no Norte e no Nordeste do Brasil, que deixaram milhares de desabrigados, também contribuiu para a redução de matérias de C\&T desse mês. Em junho, a queda do avião da Air France na costa brasileira e a morte do cantor Michael Jackson também atraíram uma cobertura ampla do JN.

Já Noticias Caracol teve uma concentração elevada de matérias de ciência em fevereiro (26,3\%) - justamente um dos meses com menos matérias no JN -, com picos mais discretos em julho, maio e dezembro $(15,7 \%, 13,2 \%$ e 13,2\%). Chama atenção ainda o fato de, em agosto, não ter sido observada nenhuma matéria científica em Noticias Caracol. É difícil vislumbrar uma decisão editorial que justifique tal discrepância, sobretudo porque as matérias de ciência transmitidas em fevereiro abordaram temas muito distintos entre si - ou seja, a transmissão não foi marcada por um evento específico que gerou uma cobertura mais intensa -, como o uso desnecessário de óculos, o acoplamento de uma estação espacial, análises de DNA que revelaram os motivos da morte de Tutancâmon, divulgação do Museu do Caribe etc. Por outro lado, nesse telejornal, foi observado algo similar ao ocorrido no programa brasileiro no que diz respeito ao tratamento dado às informações sobre o vírus A/H1N1: a maioria das matérias não cumpriu os critérios necessários para caracterizá-las como matéria de ciência.

No que diz respeito às áreas de conhecimento abordadas nas matérias, os telejornais seguiram tendências parecidas, com exceção da área de engenharias e tecnologias (Gráfico 2). Em ambos os telejornais, medicina e saúde foram as áreas de conhecimento mais recorrentes entre as matérias científicas, com destaque para o Jornal Nacional, em que tais notícias representaram quase a metade de todo o corpus (44,2\%), em comparação aos $23,7 \%$ observados no Noticias Caracol. Em segundo lugar nos dois telejornais estiveram as notícias envolvendo ciências ambientais, ciências biológicas e ciências exatas e da Terra. No JN, também em segundo lugar ficaram as engenharias e tecnologias, que em NC representaram apenas 2,6\%.

É interessante notar ainda que as ciências agrárias estiveram ausentes tanto do Jornal Nacional quanto de Noticias Caracol, especialmente se considerando que se trata de dois países com importante produção agrícola, sobretudo o Brasil. No caso do JN, estaria essa ausência relacionada ao fato de que a Rede Globo tem em sua grade de programação o Globo Rural, em que se abordam com profundidade as matérias científicas sobre essa área de conhecimento? 
No caso colombiano, as matérias relacionadas a essa área de conhecimento seriam abordadas sob perspectivas mais "políticas" que "científicas", portanto, não incluídas em nosso corpus? Para confirmar essas hipóteses, seria necessário explorar a questão com mais detalhe e talvez abordá-las em um estudo específico com essa temática.

Gráfico 1: Proporção de matérias de C\&T veiculadas pelos telejornais ao longo dos meses analisados

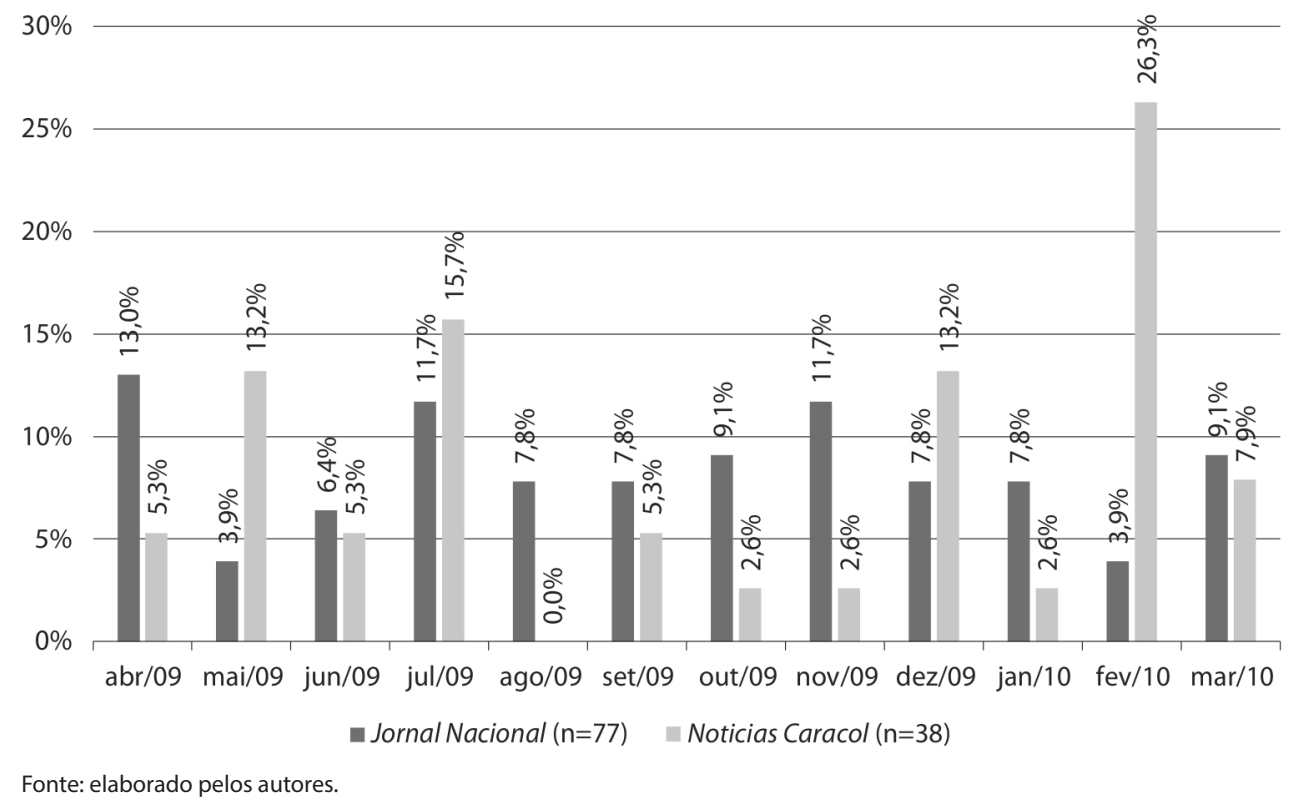

Ao levar-se em consideração estudos anteriores, a preponderância de temas sobre medicina e saúde, assim como de ciências ambientais (meio ambiente em geral), não surpreende, dado que são temas pelos quais grande parte dos cidadãos declara interesse (vide as enquetes de percepção pública da ciência em ambos os países) - uma demanda que já parecia ser atendida em alguma medida tanto pelo telejornal colombiano em particular, como se analisa em Arboleda, Hermelin e Pérez-Bustos (2011), e uma tendência midiática na Colômbia, como observam Bonilla y Cadavid-Bringe (2004), como pelo informativo brasileiro (Ramalho, 2013). Além disso, em Daza (2009) já se havia destacado como as pessoas se mostram preocupadas e apropriadas de conhecimento científico e tecnológico quando se trata de medicina e saúde, e meio ambiente.

Sobre medicina e saúde, particularmente, estudos realizados no Reino Unido (Durant, Evans, Thomas, 1992), Canadá (Einsiedel, 1992) e Itália (Bucchi, Mazzolini, 2003) já demonstraram que tal área domina o imaginário social do público no que diz respeito à ciência e constitui, assim, uma área paradigmática da ciência em geral, fenômeno que foi denominado por Bauer (1998) "medicalização das notícias de ciência". Além disso, medicina e saúde formam um campo da ciência no qual o público consegue perceber uma relação direta com seu cotidiano (León, 2008). Afinal, trata-se de matérias relacionadas com implicações individuais ou coletivas que são reais ou pelo menos potenciais (Hermelin, 2012; MondragónPerez, Hermelin, Moreno-Lodoño, 2013). 
No caso de ciências ambientais, conforme comentam Arboleda, Hermelin e Pérez-Bustos (2011) e Hermelin (2012), nota-se que os públicos se sentem bastante reconhecidos em notícias desse tema, pois também costumam estar relacionados com acontecimentos que afetam o cotidiano, sobretudo quando tratam de eventos climáticos extremos. É importante destacar também que, no período analisado, foi realizada a Conferência das Nações Unidas sobre Mudanças Climáticas (COP-15), que ocorreu em novembro de 2009 e despertou interesse na imprensa mundial.

Gráfico 2: Proporção de matérias em cada telejornal, segundo a área de conhecimento abordada

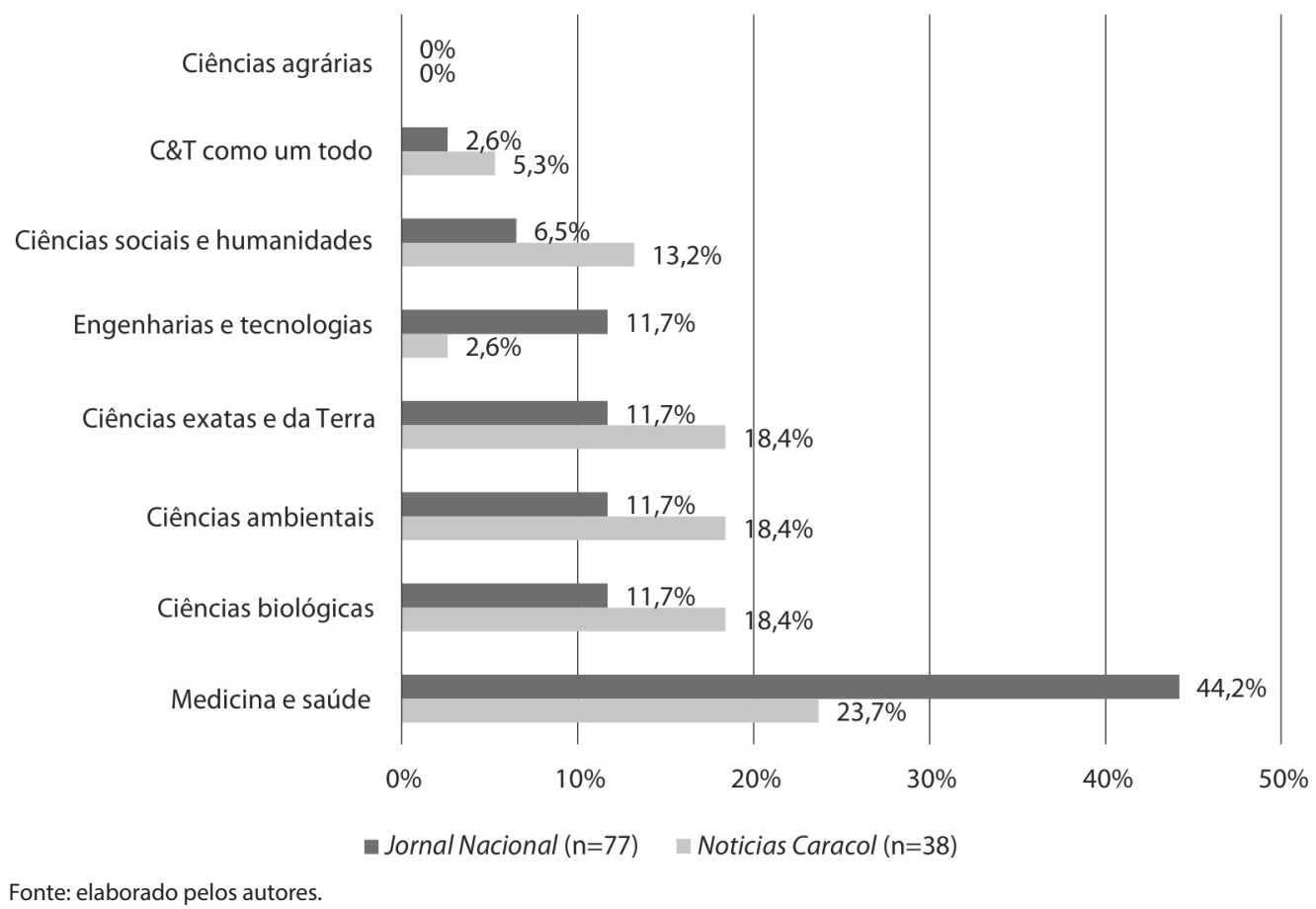

Do ponto de vista da construção narrativa das matérias, buscou-se identificar quais enquadramentos (frames, na acepção original em inglês) eram explorados nas notícias. Ao analisar os enquadramentos adotados, busca-se verificar os elementos centrais das matérias, de modo a identificar os principais enfoques empregados pelos jornalistas (Gans, 1979; Gamson, Modigliani, 1989). Segundo o protocolo aplicado, de uma lista de 11 possíveis enquadramentos, cada matéria poderia apresentar até três. Em ambos os telejornais, o enquadramento de "nova pesquisa" - quando o enfoque está no anúncio de novas investigações, novos resultados ou avanços tecnológicos - foi o mais frequente (em 67,5\% no JN e em 19,2\% de NC), como ilustra o Gráfico 3, o que não surpreende, dado o fato de que os dois telejornais priorizam as hard news - matérias factuais, ou seja, que destacam fatos novos -, apesar de que a variação de resultados de ambos os países sugere diferenças importantes nas prioridades midiáticas e seus contextos. No entanto, o segundo enfoque mais frequente no Jornal Nacional foi de "impacto de C\&T" (15\%) - quando são descritos 
os impactos (positivos ou negativos) de uma pesquisa sobre o cotidiano da sociedade -, quase empatado com o enquadramento de "antecedentes científicos" (14,3\%) - quando, por exemplo, são descritas pesquisas anteriores ou são recapitulados resultados e conclusões já conhecidas. Isso demonstra uma preocupação do JN, ainda que moderada, por contextualizar os temas científicos abordados.

Já em Notícias Caracol, o segundo enquadramento mais frequente foi o de "estratégia política, políticas públicas e regulação" (16,4\% dos enquadramentos observados), quando a notícia enfoca estratégias ou deliberações políticas envolvendo ciência, o que denota uma relação estreita entre ciência e decisões do âmbito governamental. Em seguida, foram mais frequentes os frames "ética/moral" e "cultural" (ambos representando 9,6\% dos frames). Só então aparecem os enquadramentos de "antecedentes científicos" e "impacto de C\&T" (ambos com 8,2\%), o que demonstra que a contextualização do acontecimento científico não é muito abordada.

Considerando abordagens de Dunwoody (2008), é importante ressaltar, por um lado, que a utilização mais frequente do enquadramento de "nova pesquisa" no corpus dos dois países reflete um desejo de explicar os processos do "mundo real", o que funciona muito bem para atrair a atenção do público. Nesse caso, a maneira com que se selecionam e se abordam as notícias é similar às matérias de outros assuntos - o foco prioritário seria a novidade. Isso pode estar relacionado ao fato de que a definição de notícia seria mais influenciada pelas condições de produção do meio de comunicação do que pela relevância dos temas tratados. No caso dos meios de comunicação eletrônicos, como a televisão, os ritmos de produção de conteúdo são muito acelerados, o que se refletiria na curta duração da notícia, que viria a influenciar a maneira de apresentar as novidades para atrair a atenção do público no tempo determinado.

Por outro lado, o fato de que, no caso da Colômbia, o segundo enquadramento mais presente seja o de "estratégia política, políticas públicas e regulação" indicaria que, para esse telejornal, tem mais relevância para sua emissão aquela ciência que passa pelo filtro, ou se coloca a serviço, dos interesses do governo, com o qual se corrobora a inclinação governista dos telejornais de maior audiência na Colômbia (Bonilla, Cadavid-Bringe, 2004; GómezGiraldo et al., 2010).

Observou-se também se as matérias de C\&T veiculavam imagens de cientistas, na busca de verificar se tais imagens favoreciam uma concepção estereotipada desses profissionais. As opções de locais previamente definidas no protocolo eram: "laboratório", "escritório", "locais onde realizam estudos de campo", "coletiva de imprensa" e "outros". Destacaramse no Jornal Nacional os ambientes de escritório, que representaram 30,2\% dos locais observados, seguidos pelos laboratórios: 25,4\% (Gráfico 4). Em Noticias Caracol, os locais onde os cientistas foram retratados variaram tanto que a opção "outros" representou mais da metade do corpus (51,6\%). Vale ressaltar que, no JN, dentre a opção "outros", destacou-se o local "estúdio de TV" (23,1\% do total de locais enquadrados como "outros"), que não estava previsto no protocolo. Já em NC, "outros" incluíam, por exemplo, espaços públicos como parques e praças, auditórios, corredores, estação espacial. Assim, não se pode afirmar que o local onde são retratados os cientistas nesses telejornais reforça o estereótipo do profissional de hard science cercado por vidrarias e aparatos pouco familiares ao telespectador. 
Gráfico 3: Proporção de enquadramentos adotados nas matérias de C\&T de cada telejornal

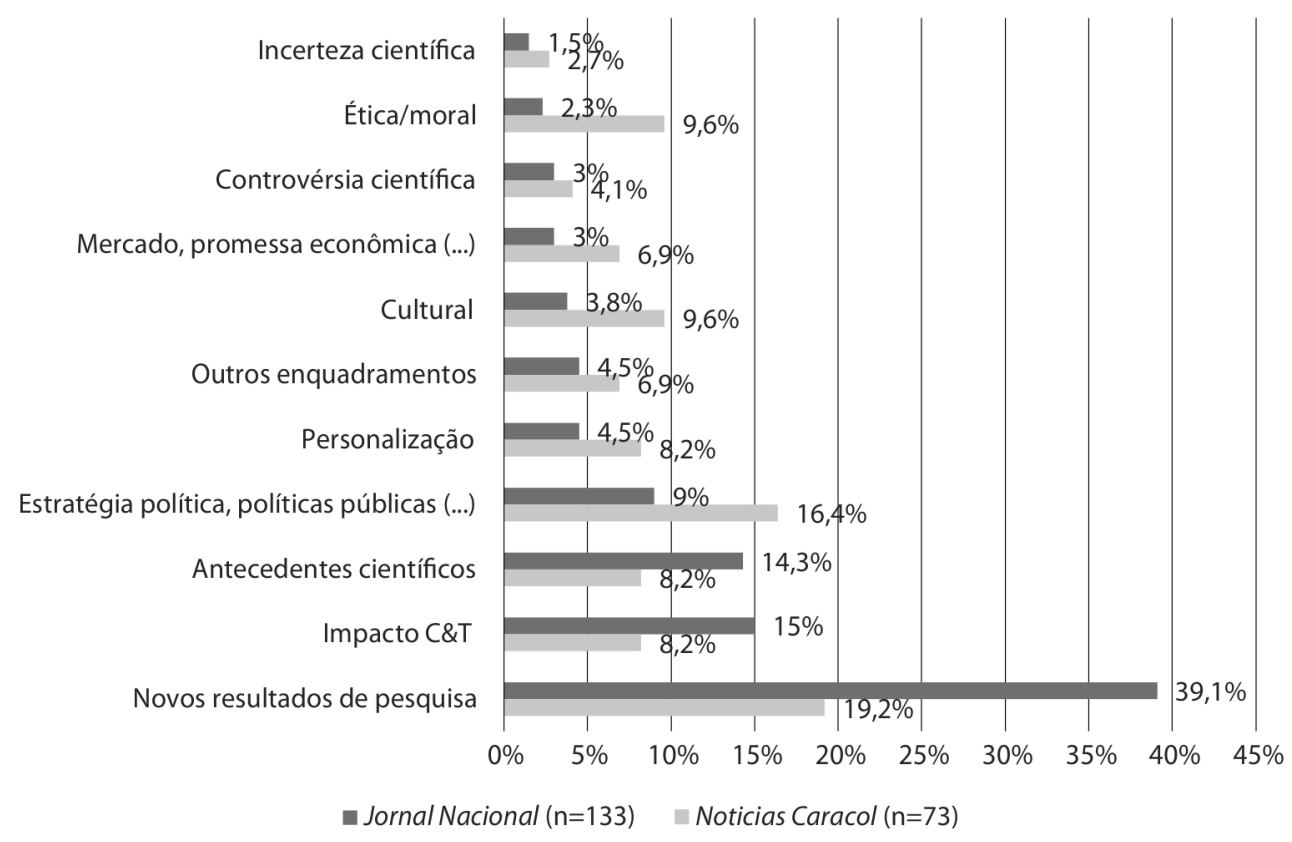

Fonte: elaborado pelos autores.

Obs.: Cada matéria poderia apresentar até três enquadramentos. Por isso, o número de enquadramentos observados (133 no $\mathrm{JN}$ e 73 em NC) é superior ao número de matérias em cada telejornal.

\section{Gráfico 4: Proporção de locais onde são retratados os cientistas por telejornal}

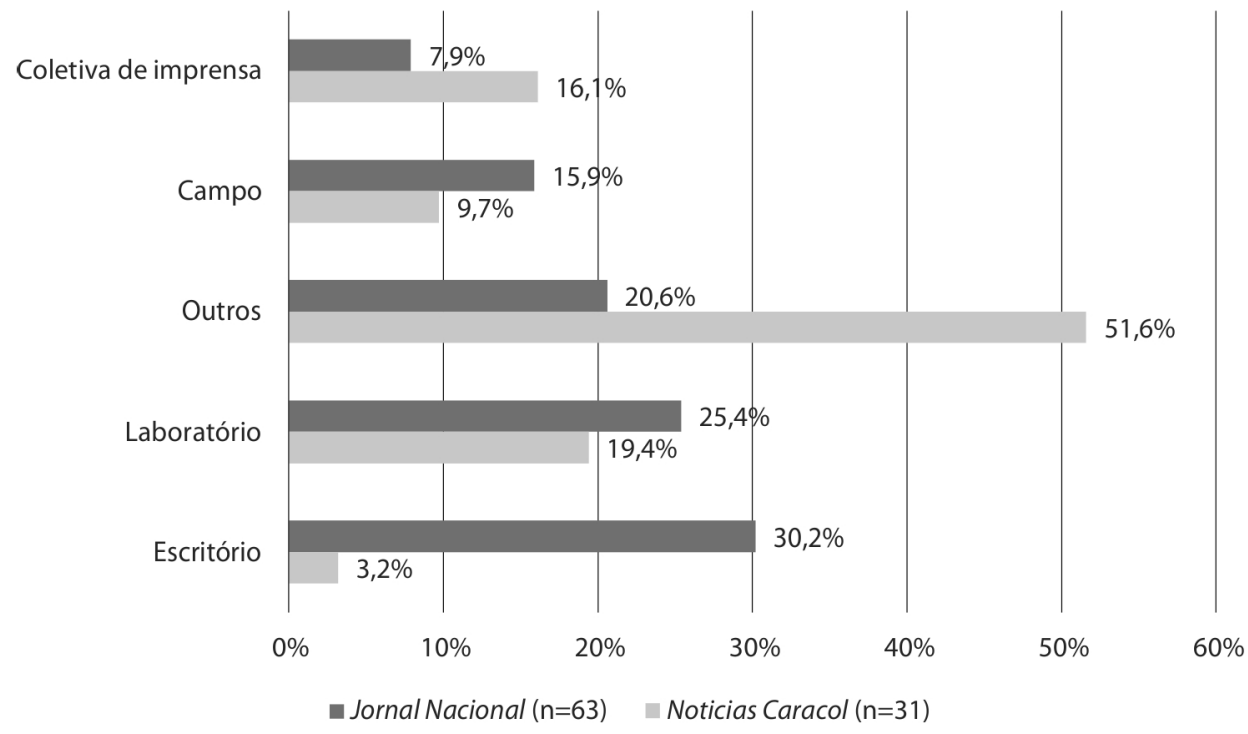

Fonte: elaborado pelos autores.

Obs.: $\mathrm{O}$ " $n$ ", nesse caso, refere-se à quantidade de imagens identificadas de cientistas. 
Além das imagens de cientistas, o protocolo utilizado buscou averiguar se as matérias de C\&T exibiam outros recursos visuais, como animações, tabelas de dados, infográficos, mapas e esquemas. No caso de matérias científicas, essas ferramentas costumam ser empregadas para facilitar o entendimento dos conteúdos. No Jornal Nacional, 39\% das matérias usaram pelo menos um desses recursos. Já em Noticias Caracol, observou-se uma proporção menor: $26,3 \%$. Vale apontar que, para estudos futuros, poderia ser interessante incorporar uma análise detalhada das diversas "imagens de ciência", a partir de aproximações semióticas como a de Sicard (1997). Ainda com relação a estratégias para facilitação de entendimento do conteúdo por parte do telespectador, observou-se se as matérias explicavam termos científicos quando os utilizavam. Das 31 matérias do JN em que foram identificados termos científicos, vinte $(64,5 \%)$ contaram com explicações. Já em NC, das 24 matérias que mencionaram termos científicos, 13 (54,2\%) os explicaram. Entretanto, é importante ressaltar que não foi analisada a correção de tais explicações. Uma parcela das matérias do Jornal Nacional também ofereceu recomendações aos telespectadores: 15 (19,5\%). A maioria dessas notícias (11) tratava de temas de medicina e saúde, o que não surpreende, já que foram frequentes as matérias sobre bem-estar que davam dicas sobre vida saudável e prevenção de doenças. Uma proporção maior de matérias em Noticias Caracol ofereceu tais recomendações (34,2\%). Dessas, se igualaram em número as de medicina e saúde e as de ciências ambientais (ambas representaram 30,8\% desse universo). A presença de recomendações em tais notícias contribui para reforçar a relação que os telespectadores traçam dessas áreas científicas com seu cotidiano. No caso das notas sobre ciências ambientais, as recomendações giraram em torno de como agir em casos de fenômenos climáticos extremos, como erupção de vulcões e geadas, ou como evitar o desmatamento.

Buscou-se verificar também se as matérias de ciência tinham uma abordagem positiva, negativa ou neutra. Para isso, registrou-se se cada matéria mencionava benefícios concretos da ciência, promessas futuras, danos concretos e/ou riscos em potencial da atividade científica. No Jornal Nacional, verificou-se que a abordagem foi mais positiva do que negativa, já que 34 delas $(44,2 \%$ do total) mencionaram promessas e/ou benefícios da ciência, enquanto apenas sete $(9,1 \%)$ trataram de riscos e/ou danos resultantes da atividade científica. Entre as matérias que citaram promessas e/ou benefícios, as de medicina e saúde foram a maioria: 17 matérias (50\% do total). A abordagem positiva por parte de Noticias Caracol foi ainda mais acentuada: 32 (84,2\%) mencionaram promessas e/ou benefícios, enquanto 17 $(44,3 \%)$ matérias mencionaram riscos e/ou promessas. Das notícias que citaram promessas e/ou benefícios da ciência, as de medicina e saúde (sete notas) e as de ciências ambientais (também sete) foram as mais frequentes: 21,9\%.

Possíveis controvérsias da ciência - expressas pela diferença de opiniões entre especialistas ou pelo embate de teorias - foram ainda menos citadas do que riscos e danos. Apenas três matérias de Noticias Caracol citaram controvérsias (7,9\% do total), enquanto no Jornal Nacional quatro matérias as abordaram (5,2\%). Neste ponto, é importante ressaltar que, tanto para enunciações valorativas (abordagem positiva ou negativa) como para as explicativas, que facilitariam o entendimento do conteúdo, é preciso não perder de vista a relevância de combiná-las com enfoques semiodiscursivos. O trabalho de De Cheveigné (2000) oferece pistas interessantes nessa direção - o mesmo se aplica à análise de enquadramentos. 
No que diz respeito às fontes das matérias, cientistas, professores universitários e pesquisadores foram as principais fontes de informação mencionadas para construir as notícias científicas (Gráfico 5). Entre os tipos de fontes utilizadas, eles representaram 40,8\% no JN e 36,5\% em NC, o que já era esperado, visto que esses são os principais atores da atividade científica e que citá-los era um dos critérios para considerar uma matéria como sendo de ciência. O papel desses profissionais, como fontes, parece ser o de legitimar a informação oferecida. Entretanto, em segundo lugar, no JN, ficaram os cidadãos, que representaram 15,1\%, um percentual bem menor do que a fonte principal. Esses cidadãos - pessoas sem formação científica ou que não representavam nenhuma entidade de classe ou política - foram citados, em geral, dando depoimentos ou compartilhando experiências. Sua função parece ser a de humanizar os conteúdos científicos, transportá-los para o cotidiano dos telespectadores em geral. Em NC, eles representaram apenas 7,9\% dos tipos de fontes.

Em segundo lugar, em Noticias Caracol, ficaram os membros do governo, representando $25,4 \%$ dos tipos de fontes - no JN, esses representaram 9,9\%. A diferença entre a segunda fonte mais frequente e a fonte principal é bem menos acentuada do que no caso do Jornal Nacional. O fato de os membros do governo serem fontes importantes reforça a hipótese

\section{Gráfico 5: Proporção de tipos de fontes citados em cada telejornal}

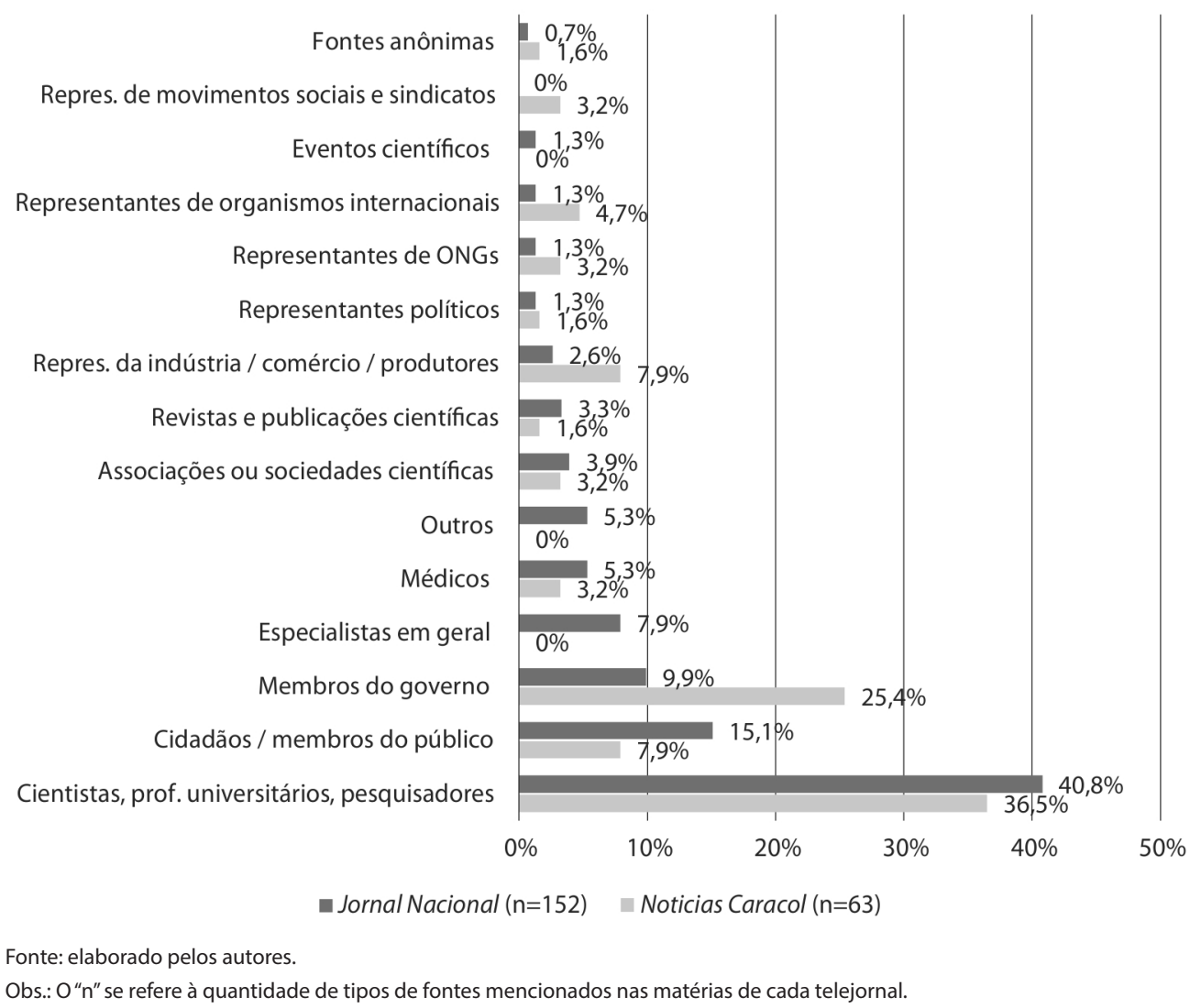


de que há uma relação próxima entre a ciência, na Colômbia, e as decisões políticas, como apontado anteriormente a respeito dos enquadramentos utilizados.

No protocolo de análise, optou-se por distinguir entre fontes e vozes. Enquanto fontes de informação são aquelas apenas citadas na notícia - em trechos como "segundo pesquisadores da instituição X" -, vozes seriam aqueles atores sociais que são explicitamente entrevistados para a matéria, ou seja, que têm sua voz e imagem aparente no vídeo. No Jornal Nacional, a proporção de vozes seguiu uma tendência parecida com a de fontes: cientistas, seguidos por cidadãos, mas especialistas em geral (especialistas que não aparecem vinculados a nenhuma instituição de pesquisa ou ensino superior) superaram por uma margem pequena os membros do governo, que, como fontes, ocupavam o terceiro lugar. É interessante notar, porém, que em Noticias Caracol, embora os cientistas sejam bem mais citados como fontes, os membros do governo aparecem com mais frequência dando entrevistas para as matérias. Como vozes, os membros do governo representam $32,4 \%$, enquanto os cientistas representam $26,5 \%$, o que demonstra, mais uma vez, o destaque dado ao âmbito político nas matérias de C\&T do telejornal colombiano.

Distinguiram-se os cientistas entrevistados entre homens e mulheres para observar se a visibilidade dada pelos telejornais a ambos os sexos era proporcional à realidade da comunidade científica em cada país. No Jornal Nacional, quase 2/3 dos 45 cientistas entrevistados $(62,2 \%)$ eram homens. Em Noticias Caracol, o desequilíbrio foi ainda maior: dos

Gráfico 6: Proporção de matérias em que aparece cada localidade de pesquisador e/ou instituição

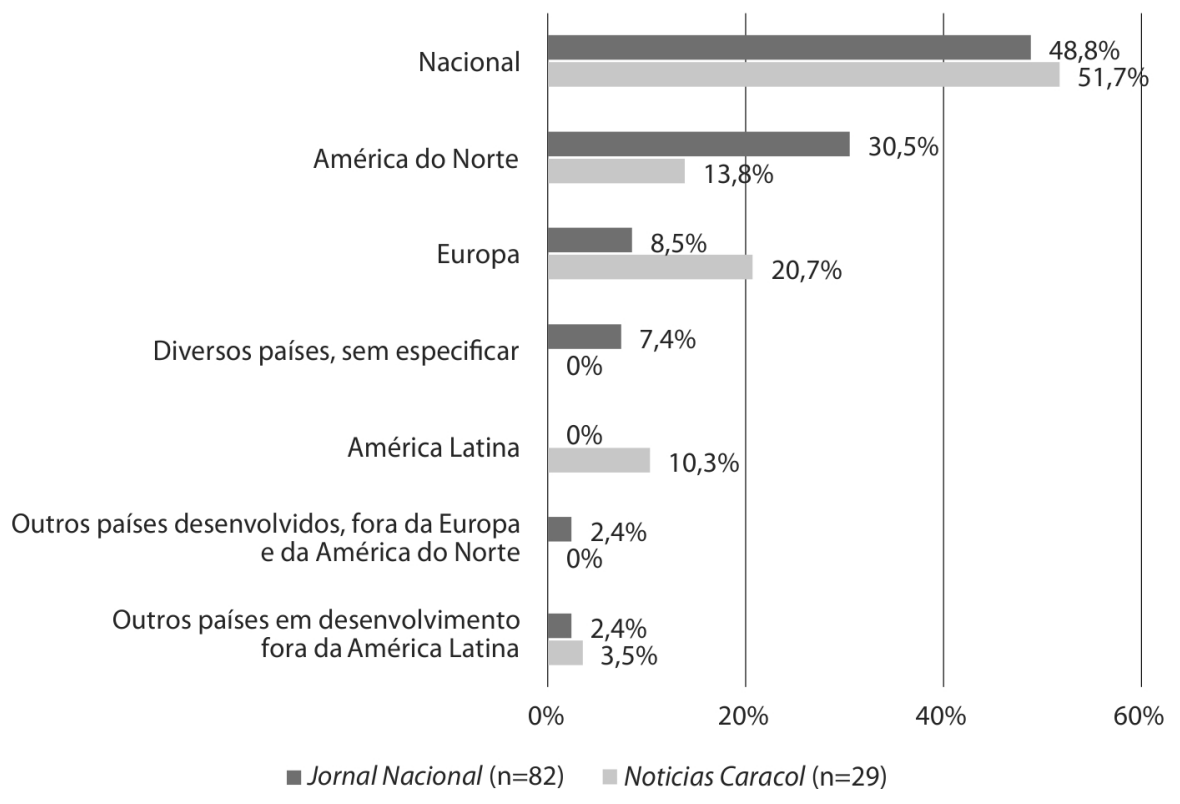

Fonte: elaborado pelos autores.

Obs.: Nesse caso, o " $n$ " se refere à quantidade de vezes que uma determinada localidade é mencionada (82 no JN e 29 em NC). Em algumas matérias, não era possível identificar tal localidade. Já em outras, mais de uma poderia ser mencionada. Por isso, o " $n$ " não coincide com o número de matérias em cada telejornal. 
51 cientistas entrevistados, 84,3\% eram homens. Em ambos os países, os dados não condizem com a realidade da comunidade acadêmica. No Brasil, segundo o último censo do Conselho Nacional de Desenvolvimento Científico e Tecnológico (CNPq, 2013), em 2010, 50\% dos pesquisadores cadastrados no diretório dos grupos de pesquisa no Brasil eram mulheres, sendo que, entre os líderes desses grupos de pesquisa, 45\% eram mulheres. Já na Colômbia, em 2010 e 2011, cerca de $44 \%$ dos cientistas ativos em grupos de pesquisa no país eram mulheres, sendo que cerca de 34\% dos líderes desses grupos eram mulheres, segundo dados do livro de indicadores de ciência e tecnologia da Colômbia de 2013 (Lucio et al., 2013). Acreditamos que a maioria de cientistas homens entrevistados possa contribuir para reforçar a associação da representação social do cientista ao estereótipo masculino, o que pode ter consequências negativas, como desestimular as meninas a seguir a carreira científica.

Buscou-se ainda identificar os locais de origem das pesquisas noticiadas. Para isso, anotaram-se os locais de trabalho dos pesquisadores ou instituições de pesquisa segundo as opções: nacional (brasileiro, no caso do JN, e colombiano, no caso de NC), América do Norte, Europa, América Latina (com exceção do Brasil, no caso do JN, ou com exceção da Colômbia, no caso de NC), outros países desenvolvidos (com exceção de América do Norte e Europa), outros países em desenvolvimento (com exceção de América Latina) e diversos países sem especificar. Em ambos os telejornais, as pesquisas feitas por pesquisadores ou instituições nacionais foram privilegiadas - representaram 48,8\% no Jornal Nacional e 51,7\% em Noticias Caracol, contrariando estudos anteriores realizados na América Latina sobre imprensa escrita, em que foi identificada uma maioria de pesquisas de países desenvolvidos (Almeida et al., 2011). Em segundo lugar, os telejornais se diferenciaram, embora, em ambos, as notícias de países desenvolvidos sejam significativas. No JN, notícias da América do Norte (sobretudo dos EUA) representam 30,5\% e da Europa, 8,5\%, o que mostra que a pauta é bem concentrada geograficamente. Em NC, é o inverso: Europa representa 20,7\% e América do Norte, 13,8\%. Chama a atenção o fato de o telejornal brasileiro não mencionar em nenhuma ocasião pesquisas conduzidas na América Latina, que, pela proximidade física e cultural, poderia em tese despertar o interesse dos telespectadores brasileiros. Em Noticias Caracol, essa localidade representou $10,3 \%$.

\section{Considerações finais}

De acordo com os dados observados, verificou-se que o telejornal brasileiro dedicou um espaço maior do que o colombiano às matérias de C\&T. Apesar de ambos os países terem tradição na área do jornalismo científico - atividade que se intensificou em alguns países da América Latina a partir de um movimento na década de 1960 impulsionado, entre outros atores, pelo espanhol Manuel Calvo Hernando (Massarani et al., 2012) -, o informativo brasileiro contou com matérias de C\&T mais longas, com mais recursos visuais, maior destaque nas edições e com uma cobertura mais estável ao longo do ano analisado. Quanto à quantidade de matérias identificadas em cada telejornal, é importante ressaltar que os critérios definidos para inclusão de uma notícia na amostra de análise - ou seja, as características que uma nota deveria apresentar para ser considerada uma matéria de ciência - tendem a privilegiar as notícias em que a C\&T aparece de forma explícita e institucionalizada (vinculada 
a universidades e institutos de pesquisa), o que restringe em alguma medida o conceito de C\&T. Tais critérios foram desenvolvidos na tentativa de eliminar subjetividades e permitir a construção de amostras homogêneas. Matérias em que a ciência era mencionada de maneira mais tácita - transversal a outras problemáticas - tendem a ser excluídas da amostra. Assim, telejornais que priorizam esse tipo de abordagem costumam apresentar menos matérias de ciência da forma como foram consideradas neste estudo, como é o caso de Noticias Caracol, em que conteúdos científicos perpassam, mais implicitamente, matérias sobre outros temas centrais (Arboleda, Hermelin, Pérez-Bustos, 2011), sem recorrer com tanta frequência a atores ou fontes da comunidade acadêmica.

Uma hipótese para essa diferenciação no tratamento da C\&T pelo telejornal nesses dois países em particular pode ser o fato de a ciência estar mais fortemente institucionalizada no Brasil do que na Colômbia (Ramalho et al., 2012). Esses processos de institucionalização, para Godin e Gingras (2000), existem quando diversas instituições contemplam questões relativas à apropriação da ciência por meio de seus mandatos financeiros, de regulação, de coordenação, de comunicação ou de educação. A soma dessas atividades constitui o aspecto coletivo da cultura de C\&T. A presença ou ausência dessas atividades ilustra um maior ou menor grau de apropriação coletiva de investimento na cultura científica e tecnológica.

Em comum, ambos os informativos priorizaram a divulgação de novas pesquisas ou resultados - o que mostra a relevância dada pelos programas às hard news -, com maior ênfase em temas de medicina e saúde, uma tendência já identificada em estudos internacionais. Nos dois telejornais, a abordagem em torno da ciência tendeu a ser mais positiva do que negativa, e a menção a controvérsias da ciência foi bastante reduzida nos dois programas televisivos, o que tende a limitar o debate público sobre a ciência, já que não a retrata como algo passível de questionamento e em constante definição. Nesse sentido, também foram muito pouco explorados os enquadramentos de "controvérsia científica" e "incerteza científica".

Contrariando tendência observada em estudos sobre a cobertura científica em jornais impressos latino-americanos, ambos os telejornais priorizaram as notícias sobre ciência nacional - uma característica positiva, já que permite que os telespectadores tenham contato com a produção científica de seus países, o que poderia, inclusive, contribuir para estimular a procura da carreira científica pelos jovens. No entanto, dado que no caso colombiano se privilegia a fonte do governo em temas de C\&T e levando em conta a questão das relações de poder que poderiam estar em jogo no desenvolvimento da atividade científica no país, cabe indagar qual é o tipo de relação existente entre os atores do governo e os pesquisadores nas notícias do corpus e os fins que perseguem. Entretanto, quando a matéria não está focada na ciência nacional, os holofotes se voltam para a ciência de países desenvolvidos - a menção a pesquisas de outros países da América Latina foi bastante reduzida ou mesmo inexistente.

Identificamos, em ambos os telejornais, grande disparidade na visibilidade dada a cientistas mulheres e homens, sendo que, em Notícias Caracol, o número de entrevistados do sexo masculino chegou a $84 \%$ em comparação aos do sexo feminino. Esses dados reforçam resultados vistos em outros estudos acerca das representações midiáticas da ciência e dos cientistas, que destacam a representação predominantemente masculina do cientista (Long et al., 2010; Whitelegg et al., 2008) e que apontam para o potencial da mídia em reproduzir e reforçar estereótipos sociais (Lobo, Cabecinhas, 2010; Chimba, Kitzinger, 2010; Steinke, 2005). 
Estudos mostraram ainda como as representações masculinas associadas à ciência e à tecnologia influenciam a percepção de jovens mulheres e sua motivação ou possibilidades de se tornar cientistas ou ver-se como cientistas (Steinke et al., 2011; Faulkner, 2007; Ruvolo, Markus, 1992). No entanto, esse tema mereceria atenção em particular, por meio de estudos de recepção e audiências, para uma discussão dos usos sociais que os públicos, em especial os jovens, dão a diferenças de gênero nesse tipo de informações.

Também é interessante observar, na cobertura do telejornal colombiano, a relação estreita que os temas de ciência possuem com a esfera política. Isso se expressou na análise de enquadramentos, na observação de fontes e, sobretudo, de vozes: membros do governo foram os principais atores sociais convidados a dar seu depoimento nas matérias. Embora grande parte da pesquisa brasileira seja financiada pelo governo, a relação entre a atividade científica e seus aspectos políticos ou governamentais não ficam explícitos nas matérias do Jornal Nacional. Uma hipótese para explicar tal discrepância é, mais uma vez, que o grau de institucionalização da ciência em cada país - mais avançada no Brasil do que na Colômbia, como mencionado anteriormente - pode implicar que as fontes e vozes científicas no caso brasileiro reflitam certo grau de autonomia em relação às autoridades estatais.

Neste estudo, buscamos comparar a cobertura de C\&T dos telejornais mais importantes de dois países da América Latina, em que identificamos similaridades e diferenças. Trata-se de um terreno ainda pouco explorado: são necessários estudos mais sistemáticos que se dediquem a entender melhor como os diferentes países da região cobrem temas de ciência. Só assim seria possível lançar luz sobre uma questão ainda mais ampla, em aberto: se seria possível falar em um jornalismo científico latino-americano, com características regionais que se distinguem de outras regiões. Para tal, acreditamos que o protocolo aqui utilizado pode ser bastante enriquecedor quando aplicado a telejornais de diferentes países do continente, já que foi desenvolvido especialmente para contemplar as diferenças e idiossincrasias observadas em programas informativos de diferentes países latino-americanos.

\section{AGRADECIMENTOS}

Este artigo é parte de um projeto desenvolvido entre o Núcleo de Estudos da Divulgação Científica do Museu da Vida/Casa de Oswaldo Cruz/Fiocruz, no Rio de Janeiro, Departamento de Comunicação da Faculdade de Comunicação e Linguagem da Pontifícia Universidade Javeriana (Bogotá) e o Programa de Comunicação Social e do Departamento de Ciências Humanas da Universidade Eafit (Medellín). O projeto conta com apoio do Departamento Administrativo de Ciência, Tecnologia e Inovação (Colciencias) da Colômbia, com recursos do Patrimônio Autônomo Fundo Nacional de Financiamento para a Ciência, Tecnologia e Inovação, Francisco José de Caldas, da Colômbia, e do Conselho Nacional de Desenvolvimento Científico e Tecnológico (CNPq) do Brasil. Está ligado ainda à Rede Ibero-americana de Monitoramento e Capacitação em Jornalismo Científico (www.museudavida.fiocruz.br/redejc).

\section{NOTAS}

${ }^{1}$ No caso de Noticias Caracol, a liderança de audiência é disputada de perto com outro telejornal, o Noticias
$R C N$, que pertence a outro canal privado nacional de sinal aberto na Colômbia. No momento de seleção
dos programas a analisar, Noticias Caracol estava, por pouco, em primeiro lugar, segundo o Estudio General
de Medios (EGM), publicado na página oficial da Comisión Nacional de Televisión, atualmente Autoridad
Nacional de Televisión (www.antv.gov.co).
${ }^{2}$ É importante ressaltar que no corpus de matérias analisadas de Noticias Caracol (que excluiu os domingos)
foram encontradas 38 notícias de ciência em 72 edições do programa, como se verá mais adiante, uma média 
de 0,527 matéria por edição. Aos domingos foram observadas seis notícias, totalizando 44 matérias em 84 edições, uma média de 0,523 matéria por edição. Como não houve diferença significativa, acredita-se que a eliminação dos domingos neste estudo comparativo não tenha introduzido vieses nos dados apresentados.

${ }^{3}$ Neste estudo não se fez distinção entre gêneros jornalísticos, como nota, crônica, reportagem ou entrevista, pois não se chegou a critérios objetivos que dessem conta das diferenças narrativas e de culturas jornalísticas em ambos os países. Por isso, foi utilizado recorrentemente o termo "matéria", mais genérico.

\section{REFERÊNCIAS}

ALBERGUINI, Audre Cristina.

A ciência nos telejornais brasileiros: o papel educativo e a compreensão pública das matérias de CT\&I. Tese (Doutorado em Comunicação Social) - Universidade Metodista de São Paulo, São Bernardo do Campo. 2007.

ALMEIDA, Carla et al.

La cobertura de la ciencia en América Latina: estudio de periódicos de elite en nueve países de la región. In: Moreno, Carolina (Org.). Periodismo y divulgación científica: tendencias en el ámbito iberoamericano. Madrid: Organización de Estados Iberoamericanos; Biblioteca Nueva. p.75-97. 2011.

AMORIM, Luís Henrique; MASSARANI, Luisa. Jornalismo científico: um estudo de caso de três jornais brasileiros. Revista Brasileira de Ensino de Ciência e Tecnologia, v.1, n.1, p.73-84. 2008.

ANDRADE, Lacy Varella Barca de.

Iguarias na hora do jantar: o espaço da ciência no telejornalismo diário. Rio de Janeiro: UFRJ. Tese (Doutorado) - Instituto de Bioquímica, Universidade Federal do Rio de Janeiro, Rio de Janeiro. 2004.

ARBOLEDA, Tania et al.

Ciencia y tecnología en los telediarios colombianos: sobre lo que se cubre y no se cubre. Ensaio Pesquisa em Educação em Ciências, v.17, n.1, p.208-229. 2015.

ARBOLEDA, Tania; HERMELIN, Daniel; PÉREZBUSTOS, Tania.

La cobertura de la ciencia en los noticieros colombianos: del análisis de resultados a las reflexiones metodológicas para su investigación. Ensaio Pesquisa em Educação em Ciências, v.13, n.3, p.151-166. 2011.

BAUER, Martin.

The medicalization of science news: from the "rocket-scalpel" to the "gene-meteorite" complex. Social Science Information, v.37, n.4, p.731-751. 1998.

BAUER, Martin; RAGNARSDÓTTIR, Ásdis G.; RÚDÓLFSDÓTTIR, Annadís G.

Science and technology in the British press, 19461990: a systematics content analysis of the press. Workreport. [s.l.]: [s.n.] 1993.
BID.

Banco Interamericano de Desarrollo. Disponível em: http://www.iadb.org/es/investigacion-ydatos//tablas,6882.html?indicator=4. Acesso em: 24 nov. 2014. 2014.

BONILLA, Jorge Iván; CADAVID-BRINGE, Amparo.

¿Qué es noticia? Agendas, periodistas y ciudadanos. Bogotá: Pontificia Universidad Javeriana; Fundación Konrad Adenauer. 2004.

BRASIL.

Ministério da Ciência, Tecnologia e Inovação; Centro de Gestão e Estudos Estratégicos. Percepção pública da C\&T no Brasil: ciência e tecnologia no olhar dos brasileiros. Sumário executivo. Disponível em: http://percepcaocti. cgee.org.br/wp-content/themes/cgee/files/ sumario.pdf. Acesso em: 15 mar. 2016. 2015

BUCCHI, Massimiano; MAZZOLINI, Renato G. Big science, little news: science coverage in the Italian daily press, 1946-1997. Public Understanding of Science, v.12, n.1, p.7-24. 2003.

BUSTOS MORA, Giselle.

Ciencia y tecnología en la prensa costarricense: análisis de casos. Revista de Ciencias Sociales, v.4, n.106, p.215-229. 2004.

CHIMBA, Mwenya; KITZINGER, Jenny.

Bimbo or boffin? Women in science: an analysis of media representations and how female scientists negotiate cultural contradictions. Public Understanding of Science, v.19, n.5, p.609-624. 2010.

CNPq. Conselho Nacional de Desenvolvimento Científico e Tecnológico. Número de mulheres cientistas já iguala o de homens. Disponível em: http://www.cnpq.br/web/guest/ noticiasviews/-/journal_content/56_INSTANCE_ a6MO/10157/905361. Acesso em: 15 ago. 2013. 6 mar. 2013.

DANE.

Departamento Administrativo Nacional de Estadística de Colômbia. Disponível em: https:// www.dane.gov.co/index.php/estadisticassociales/pobreza. Acesso em: 24 nov. 2014. 2014. 
DAZA-CAICEDO, Sandra; LOZANO-BORDA, Marcela (Ed.).

Percepciones de las ciencias y las tecnologías en Colombia. Resultados de la tercera Encuesta Nacional de Percepción Pública de la Ciencia y la Tecnología. Bogotá: Observatorio Colombiano de Ciencia y Tecnología. 2014.

DAZA, Sandra (Ed.).

Percepciones sobre la ciencia y la tecnología en Bogotá. Bogotá: Observatorio Colombiano de Ciencia y Tecnología. 2009.

DE CHEVEIGNÉ, Suzanne.

L'environnement dans les journaux télévisés: médiateurs et visions du monde. Paris: CNRS Éditions. 2000.

DUNWOODY, Sharon.

Science journalism. In: Bucchi, Massimiano; Trench, Brian (Ed.). Handbook of public communication of science and technology. London: Routledge. p.15-26. 2008.

DURANT, John; EVANS, Geoffrey; THOMAS, Geoffrey.

Public understanding of science in Britain: the role of medicine in the popular representation of science. Public Understanding of Science, v.1, n.2, p.161-182. 1992.

EINSIEDEL, Edna F.

Framing science and technology in the Canadian press. Public Understanding of Science, v.1, n.1, p.89-103. 1992.

FAULKNER, Wendy.

Nuts and bolts and people: gender-troubled engineering identities. Social Studies of Science, v.37, n.3, p.331-356. 2007.

GAMSON, William A.; MODIGLIANI, Andre. Media discourse and public opinion on nuclear power: A constructionist approach. American Journal of Sociology, v.95, n.1, p.1-7. 1989.

GANS, Herbert.

Deciding what's news. New York: Pantheon. 1979.

GLOBO.

Globo Comunicação e Participações S.A. About Globo. Disponível em: https://globoir.globo. com/show.aspx?idCanal=eYO3NapXyNrfzSKIWV $\mathrm{wGbQ}==$. Acesso em: 2 jul. 2013.9 jul. 2012.

GODIN, Benoit; GINGRAS, Yves.

What is scientific and technological culture and how is it measured? A multidimensional model. Public Understanding of Science, v.9, n.1, p.43-58. 2000.

GÓMEZ-GIRALDO, Juan Carlos et al. Los noticieros de la televisión colombiana "en observación": una mirada desde la academia a la estructura, cobertura y contenidos de los teleinformativos de la televisión abierta en Colombia. Palabra Clave, v.13, n.2, p.217-250. 2010.

GÖPFERT, Winfried.

Scheduled science: TV coverage of science, technology, medicine and social science and programming policies in Britain and Germany. Public Understanding of Science, v.5, n.4, p.361374. 1996.

HANSEN, Anders; DICKINSON, Roger. Science coverage in the British mass media: media output and source input. Communications, v.17, n.3, p.365-377. 1992.

HERMELIN, Daniel.

Los estudios de recepción en la formación e investigación sobre periodismo científico en Latinoamérica. In: Massarani, Luisa (Ed.). Monitoramento e capacitação em jornalismo científico: a experiência de uma rede iberoamericana. Rio de Janeiro: Museu da Vida/Casa de Oswaldo Cruz; Quito: Centro Internacional de Estudios Superiores de Comunicación para América Latina. p.77-92. 2012.

HERMELIN, Daniel.

La comunicación pública de la ciencia y la tecnología en la formación en comunicación social y en otras áreas del conocimiento. Trilogía, n.5, p.107-120. 2011.

HIJMANS, Ellen; PLEIJTER, Alexander; WESTER, Fred.

Covering scientific research in Dutch

newspapers. Science Communication, v.25, n.2, p.153-176. 2003.

IBGE.

Instituto Brasileiro de Geografia e Estatística.

Pesquisa Nacional por Amostra de Domicílios, Brasil e Síntese de Indicadores, 2013. Disponível em: http://www.ibge.gov.br/home/presidencia/ noticias/imprensa/ppts/00000018883109232014 310419410583.pdf. Acesso em: 18 nov. 2014. 18 set. 2014.

KRIPPENDORFF, Klaus

Metodología de análisis de contenido: teoría y práctica. Barcelona: Paidós. 1990.

LEHMKUHL, Markus et al.

Scheduling science on television: a comparative analysis of the representations of science in 11 European countries. Public Understanding of Science, n.21, v.8, p.1002-1018. 2012.

LEÓN, Bienvenido.

Science-related information in European television: a study of prime-time news. Public Understanding of Science, v.17, n.4, p.443-460. 2008. 
LIVRO AZUL...

Livro azul da quarta Conferência Nacional de Ciência, Tecnologia e Inovação para o Desenvolvimento Sustentável. Brasília: Ministério da Ciência, Tecnologia e Inovação/Centro de Gestão e Estudos Estratégicos. Disponível em: http://www.cgee.org.br/publicacoes/livroazul. php. Acesso em: 11 nov. 2014. 2010.

LOBO, Paula; CABECINHAS, Rosa.

The negotiation of meanings in the evening news: towards an understanding of gender disadvantages in the access to the public debate. International Communication Gazette, v.72, n.4-5, p.339-358. 2010.

LONG, Marileeet al.

Portrayals of male and female scientists in television programs popular among middle school-age children. Science Communication, v.32, n.3, p.356-382. 2010.

LOZANO, Marcela.

Programas y experiencias en popularización de la ciencia y la tecnología: panorámica desde los países del Convenio Andrés Bello. Bogotá: Convenio Andrés Bello. 2005.

LOZANO-BORDA, Marcela; MALDONADO, Oscar Javier.

Estrategia Nacional de Apropiación Social de la Ciencia, la Tecnología y la Innovación. Bogotá: Colciencias. 2010.

LUCIO, Jorge et al.

Indicadores de ciencia y tecnología Colombia 2013. Bogotá: Observatorio Colombiano de Ciencia y Tecnología. 2013.

MASSARANI, Luisa; BUYS, Bruno.

Cuando la ciencia es noticia: una evaluación de la sección de ciencia en nueve países de América Latina y el Caribe. In: Lozano, Mónica; SánchezMora, Carmen (Ed.). Evaluando la comunicación de la ciencia: una perspectiva latinoamericana. México: Cyted; Aeci; DGDC/Unam. p.115-128. 2008.

MASSARANI, Luisa et al.

Periodismo científico: reflexiones sobre la práctica en América Latina. Chasqui, n.120, p.7377. 2012.

MASSARANI, Luisa et al.

Science journalism in Latin America: a case study of seven newspapers in the region. Journal of Science Communication, v.4, n.3, p.1-8. 2005.

MEDEIROS, Flavia Natércia da Silva; MASSARANI, Luisa.

A cobertura da gripe A(H1N1) 2009 pelo

Fantástico. Intercom, v.34, n.1, p.41-59. 2011.
MEDEIROS, Flavia Natércia da Silva; RAMALHO, Marina; MASSARANI, Luisa.

A ciência na primeira página: análise das capas de três jornais brasileiros. História, Ciências, Saúde - Manguinhos, v.17, n.2, p.439-454. 2010.

MONDRAGÓN-PEREZ, Lina; HERMELIN, Daniel; MORENO-LONDOÑO, Juanita.

La gripa H1N1 y los noticieros de TV en Colombia: entre las representaciones del riesgo y las resonancias de imaginarios. Disertaciones, v.6, n.2, p.174-205. 2013.

PARODI, Giovanni; FERRARI, Silvana.

O discurso da ciência e da tecnologia da imprensa escrita chilena: aproximação ao corpus DICIPE-2004. Delta, v.23, n.2, p.339-369. 2007.

PELLECHIA, Marianne G.

Trends in science coverage: a content analysis of three US newspapers. Public Understanding of Science, v.6, n.1, p.49-68. 1997.

PÉREZ-BUSTOS, Tania; LOZANO-BORDA, Marcela (Ed.).

Ciencia, tecnología y democracia: reflexiones en torno la apropiación social del conocimiento. Medellín: Colciencias; Universidad Eafit. 2011.

POLINO, Carmelo; FAZIO, Maria Eugenia; CHIAPPE, Dolores.

Análisis de la oferta informativa sobre ciencia y tecnología en los principales diarios argentinos. Buenos Aires: Observatorio de Ciencia, Tecnología e Innovación Productiva; Secretaria de Ciencia y Técnica. 2006.

RAMALHO, Marina.

A ciência no Jornal Nacional e na percepção do público. Tese (Doutorado em Educação, Gestão e Difusão em Biociências) - Instituto de Bioquímica Médica, Universidade Federal do Rio de Janeiro, Rio de Janeiro. 2013.

RAMALHO, Marina; POLINO, Carmelo; MASSARANI, Luisa.

From the laboratory to prime time: science coverage in the main Brazilian TV newscast. Journal of Science Communication, v.11, n.2, p.111. 2012.

RAMALHO, Marina et al.

Ciência em telejornais: uma proposta de ferramenta para análise de conteúdo de notícias científicas. In: Massarani, Luisa; Ramalho, Marina (Ed.). Monitoramento e capacitação em jornalismo científico: a experiência de uma rede ibero-americana. Rio de Janeiro: Museu daVida/Casa de Oswaldo Cruz/Fiocruz; Quito: Centro Internacional de Estudios Superiores de Comunicación para América Latina. p.11-24. 2012. 
RONDELLI, Daniela Rubbo Rodrigues. A ciência no picadeiro: uma análise das reportagens sobre ciência no programa Fantástico. Dissertação (Mestrado em Comunicação Social) - Universidade Metodista de São Paulo, São Paulo. 2004.

ROZO, Claudia.

Representaciones de cultura científica y cultura tecnológica desde los medios de comunicación: Diario El Tiempo, caso de estudio. In: Congreso Iberoamericano de Ciencia, Tecnología, Sociedad e Innovación, 1., 2006, México, DF. Actas... México: Organización de Estados Iberoamericanos para la Educación, la Ciencia y la Cultura. p.1-19. 2006.

RUVOLO, Ann Patrice; MARKUS, Hazel Rose. Possible selves and performance: the power of self-relevant imagery. Social Cognition, n.10, v.1, p.95-124. 1992.

SICARD, Monique.

Les paradoxes de l'image. Hermès, n.21, p.45-54. 1997.

STEINKE, Jocelyn.

Cultural representations of gender and science: portrayals of female scientists and engineers in popular films. Science Communication, v.27, n.1, p.27-63. 2005

STEINKE, Jocelyn et al.

Gender differences in adolescents' wishful identification with scientist characters on television. Science Communication, v.34, n.2, p.163-199. 2011.

STEMPEL, Guido H.; WESTLEY, Bruce H. (Ed.). Research methods in mass communication. Englewood Cliffs: Prentice Hall. 1989.

TAKAHASHI, Bruno; MEISNER, Mark.

Climate change in Peruvian newspapers: the role of foreign voices in a context of vulnerability. Public Understanding of Science, v.22, n.4, p.427442. 2013.

VERHOEVEN, Piet.

Sound-bite science: on the brevity of science and scientific experts in Western European television news. Science Communication, v.32, n.3, p.330355. 2010.

WHITELEGG, Elizabeth et al.

(In)visible witnesses: investigating gendered representations of scientists, technologists, engineers and mathematicians on UK children's television. Report for the UK Resource Centre for Women in Science, Engineering and Technology. Bradford: [s.n.]. 2008.

YÚDICE, George.

Medios de comunicación e industrias culturales, identidades colectivas y cohesión social. São Paulo: Instituto Fernando Henrique Cardoso; Santiago de Chile: Corporación de Estudios para Latinoamérica. 2008. 